\title{
Nova hipótese de relacionamento filogenético entre os gêneros de Euglossini e entre as espécies de Eulaema Lepeletier, 1841 (Hymenoptera: Apidae: Euglossini)
}

\author{
Marcio Luiz de OLIVEIRA ${ }^{1}$
}

\section{RESUMO}

O gênero Eulaema Lepeletier, 1841, assim como os demais gêneros de Euglossini, é particularmente conhecido por suas relações com as orquídeas. É exclusivamente neotropical, composto de abelhas grandes (20 a $30 \mathrm{~mm}$ ), com pilosidade densa, língua longa e, diferentemente dos demais gêneros de Euglossini, sem brilho metálico na cabeça e no tórax. Até agora, quatro hipóteses de relaçōes filogenéticas entre os gêneros de Euglossini foram apresentadas, mas, em nenhuma a monofilia do gênero Eulaema ficou bem corroborada. Neste trabalho é apresentada uma nova hipótese de relação filogenética entre os gêneros de Euglossini, bem como para espécies do gênero Eulaema, que tem sua monofilia suportada pelas seguintes apomorfias: 1) projeção genal, 2) clípeo bastante elevado e formando rampas muito íngremes lateralmente, 3) linha mesoscutal saliente e 4) tergo I com comprimento equivalente a 1/3 do tergo II. O gênero Eufriesea Cockerell, 1908 é o principal candidato a grupo-irmão de Eulaema, compartilhando com este as seguintes sinapomorfias: 1) tíbias posteriores dos machos com ápice pontiagudo, 2) pilosidade pouco densa na face externa das tíbias posteriores dos machos, 3) quinto tarsômero das pernas posteriores menor que o das pernas médias, 4) esporóes da tíbia posterior aproximadamente iguais no tamanho e 5) gonocoxito com projeção ventro-lateral. Pela hipótese aqui apresentada, o gênero Eulaema é composto de dois ramos principais que correspondem aos subgêneros Apeulaema e Eulaema s. str. propostos por Moure (1950).

PALAVRAS-CHAVE

Apidae, Euglossini, Eulaema, filogenia, taxonomia.

\section{New hypothesis of phylogenetic relationships for the genera of Euglossini, and for the species of Eulaema Lepeletier, 1841 (Hymenoptera: Apidae: Euglossini)}

\begin{abstract}
The genus Eulaema as well as the other genera of Euglossini is particularly known for its interactions with orchids. It occurs exclusively in the Neotropics, and is composed of 26 species of large $(20-30 \mathrm{~mm})$, hairy, and long-tongued bees. In contrast to other Euglossini, these bees do not exhibit a metallic shine on the head and thorax. Four hypothesis of phylogenies for the genera of Euglossini have been proposed, and the monophyly of the genus Eulaema have not been corroborated. In this study, the following apomorphies support the monophyly of the genus Eulaema: 1) genal projection; 2) clypeus projected and with strong lateral ramps; 3) mesoscutal line salient and 4) tergum I with 1/3 of the tergum II length. Eufriesea Cockerell, 1908 is the most likely candidate for sister-group of Eulaema, with the following sinapomorphies supporting this clade: 1) male hindtibia with a pointed apical margin; 2) external surface of the male hindtibia with few hairs; 3) fifth hindtarsus smaller than the fifth midtarsus; 4) spurs of the hindlegs approximately equal-sized and 5) gonocoxite with a ventrolateral projection. According to the hypothesis presented here, Eulaema is composed of two main clades that correspond to the subgenera Eulaema s. str. and Apeulaema, proposed by Moure (1950).
\end{abstract}

KEY WORDS

Euglossini, Eulaema, orchid-bees, phylogeny, taxonomy.

\footnotetext{
1 Coordenação de Pesquisas em Entomologia, Instituto Nacional de Pesquisas da Amazônia, Av. André Araújo 2936, Petrópolis, caixa postal 478, 69011-970 Manaus-AM, Brasil. E-mail:mlolivei@inpa.gov.br
} 


\section{INTRODUÇÃO}

A tribo Euglossini compreende cinco gêneros de abelhas conhecidas como "abelhas das orquídeas". O gênero Euglossa Latreille, 1802 inclui mais de uma centena de espécies de tamanho pequeno a médio (8-18 $\mathrm{mm}$ ), com tegumento possuindo brilho metálico verde ou azul intensos e relativamente desprovido de pêlos. Eufriesea Cockerell, 1899 é constituído de mais 50 espécies maiores do que as do gênero anterior (14-26 mm), corpo coberto de pêlos e com tegumento de diversas cores, mas fracamente brilhante. Moure (2000) (em publicação que veio a circular em dezembro de 2003) reconhece 26 espécies para o gênero Eulaema Lepeletier, 1841, porém desconhece que duas novas espécies haviam sido descritas recentemente (Ospina-Torres \& SandinoFranco 1997, Dressler \& Ospina-Torres 1997). Oliveira (2006) reconhece 26 espécies com algumas divergências de Moure (2000). São abelhas cujo tamanho varia de 20 a $30 \mathrm{~mm}$, com pilosidade mais densa que em Eufriesea, mas com tegumento desprovido de brilho metálico na cabeça e no tórax. Exaerete Hoffmansegg, 1817 inclui 7 espécies (15-28 mm), tegumento verde brilhante intenso e parcamente revestido de pêlos como em Euglossa; as fêmeas têm sido encontradas parasitando os ninhos de Eufriesea e Eulaema. De Aglae Lepeletier \& Serville, 1825 só se conhece uma espécie, a qual apresenta tegumento pouco coberto de pêlos, brilhante e de coloração azul-esverdeado; as fêmeas parasitam exclusivamente ninhos de Eulaema.

Até esse momento, foram propostas as seguintes hipóteses sobre relaçôes filogenéticas entre os gêneros de Euglossini (Figura 10):

Porém, em nenhuma delas a monofilia do gênero Eulaema ficou bem corroborada. Além disso, o único autor a apresentar uma hipótese para relações filogenéticas entre as espécies de qualquer um dos gêneros foi Engel (1999) para o gênero Exaerete. Entretanto, a relação entre as espécies não está bem resolvida.

Assim, os objetivos deste trabalho foram apresentar uma nova hipótese para o relacionamento filogenético entre os gêneros de Euglossini, testar a monofilia do gênero Eulaema e também propor uma hipótese para o relacionamento entre as espécies que compõem esse gênero.

\section{MATERIAL E MÉTODOS}

\section{COLEÇÕES CONSULTADAS}

Foram examinados cerca de 4000 exemplares de Eulaema, pertencentes às seguintes instituições e curadores ou coleções particulares, à época: AMNH - American Museum of Natural History, New York, Jerome Rozen; CJBB - Jardim Botânico de Brasília e CUNB - Universidade de Brasília, Anthony Raw; CMNH - The Carnegie Museum of Natural History, Pittsburg, Robert Davidson; CPCS - Clemens Schlindwein; CPDD Domiciano Dias; CPGM - Gabriel A. R. Melo; CPSM - Sidney Mateus; CUIC - Cornell University Insect Collection, Ithaca,
E.R. Hoebeke; MNRJ - Museu Nacional do Rio de Janeiro, Miguel A. Monné; MPEG - Museu Paraense Emílio Goeldi, Belém, Ana Y. Harada; MRSN - Museo Regionale di Scienze Naturali, Torino, P.L. Scaramozzino; MZSP - Museu de Zoologia da Universidade de São Paulo, Carlos R. F. Brandão; DZUP Departamento de Zoologia, Universidade Federal do Paraná, Curitiba, Germano H. R. Neto; NhMW - Naturhistorisches Museum of Wien, Stefan Schodl; NZCS - National Zoological Collection of Suriname, Panamaribo, Helene Hiwatt van Laar; QCAZ - Museo de Zoologia de la Universidad Católica de Quito, Giovanni Onore; RPSP - Faculdade de Filosofia, Ciências e Letras/ USP, Ribeirão Preto, João M.F. Camargo; SEAN - Servicio Entomológico Autonomo, Leon, Nicaragua, Jean Michel Maes; SEMK - Snow Entomological Museum of Kansas, Lawrence, Robert Brooks; UCDC - University of California, Davis, S.L. Heydon; UFMA - Universidade Federal do Maranhão, São Luís, Márcia Rego; UFMG - Universidade Federal de Minas Gerais, Belo Horizonte, Fernando Amaral da Silveira; UFPE Universidade Federal de Pernambuco, Recife, Isabel Machado; UFVB - Universidade Federal de Viçosa, Lúcio A. O. Campos; UNCB - Universidad Nacional da Colombia, Bogotá, Guiomar Nates Parra; UFPB - Universidade Federal da Paraíba, João Pessoa, Celso Feitosa Martins; UFCG - Universidade Federal de Campina Grande, Patos, Fernando C. V. Zanella; ZMUC Zoological Museum, University of Copenhagem, Rudolf Meier; ZSMC - Zoologische Staatssammlung, Munique, Johannes Schubert.

\section{OBTENÇÃO DOS CLADOGRAMAS}

Foram estudados caracteres morfológicos principalmente de machos e genitália somente de machos, tanto de Eulaema como de espécies afins, que permitissem informar sobre as relações internas do gênero Eulaema e deste em relação aos outros gêneros da tribo Euglossini. Optou-se por trabalhar preferencialmente com machos, porquê são mais abundantes nas coleções.

Para obtenção dos cladogramas, foi utilizado o programa Hennig86 versão 1.5 [@ James S. Farris], com a opção "ie-" (enumeração implícita), que gera as árvores por um algoritmo exato e retém apenas uma delas, a mais parcimoniosa. Optou-se por tratar todos os caracteres multi-estados como não-aditivos. Para impressão dos cladogramas foi utilizado o programa Tree Gardener 2.2 [○ Tiago C.Ramos], sendo que os caracteres foram assinalados manualmente.

\section{RELACIONAMENTOS FILOGENÉTICOS ENTRE OS GÊNEROS DE EUGLOSSINI}

\section{Seleção de caracteres}

A maioria dos caracteres analisados foi obtida em literatura e conferido nos exemplares, principalmente nos trabalhos de Kimsey $(1982,1987)$ e Engel (1999) e serão mencionados abaixo. Somente caracteres de machos foram analisados, com exceção de 13 e 27 que são exclusivos de fêmeas. Para 
enraizamento das árvores foram utilizadas como grupo-externo, as seguintes espécies de Apidae: Bombus atratus Franklin, 1913, Apis mellifera scutelatta Lepeletier, 1836 e Melipona scutellaris Latreille, 1811.

\section{CARACTERES ESTUDADOS}

1. Tegumento da cabeça e tórax: sem brilho metálico (0); com brilho metálico (1). (IC = 50; IR = 66).

Brilho metálico no tegumento é exclusividade dos Euglossini, dentre os grupos analisados. Entretanto, está ausente no tegumento da cabeça e tórax de todas as espécies do gênero Eulaema, bem como no abdômen de todas as espécies do subgênero Apeulaema, com exceção de Eulaema nigrita Lepeletier, 1841 em seus últimos tergos metassomáticos.

2. Carena média do clípeo: ausente $(0)$; presente (1). (IC = 50; IR =0).

Todos os Euglossini possuem carenas laterais completas no clípeo, mas, carena média completa só é encontrada em Euglossa e Eulaema.

3. Saliência pós-ocelar: ausente (0); presente (1). (IC = 33; $\mathrm{IR}=0)$.

Aglae, Exaerete e Eulaema possuem uma carena bastante evidente após os ocelos e precedida de um sulco transversal adjacente.

4. Comprimento do primeiro flagelômero: menor ou quase igual ao segundo (0); maior que o segundo (1); tão longo quanto o segundo e o terceiro juntos $(2)$. ( $\mathrm{IC}=66$; IR $=50)$.

Eufriesea e Eulaema possuem o primeiro flagelômero um pouco maior que segundo, mas esse estado também ocorre em Apis mellifera (homoplasia?). Entretanto, em Euglossa ele é tão longo quanto os dois seguintes, indicando uma autapomorfia para esse gênero.

5. Projeção genal: ausente (0); presente (1). (IC = 100; IR = 100). Caráter 2 de Kimsey (1987)

Conforme tinha sido observado por Kimsey (1987), machos de Eulaema possuem uma ampla projeção truncada e dentiforme na área genal. No entanto, observou-se que machos de Euglossa intersecta Latreille, 1938 também possuem uma projeção semelhante. No cladograma, a hipótese é de que surgiram independentemente.

6. Clípeo: pouco elevado, rampas laterais pouco íngremes (0); muito elevado, rampas laterais muito íngremes (1). (IC = $100 ;$ IR $=100)$.

Clípeo com rampas laterais bastante íngremes é encontrado somente em Eulaema.

7. Palpos labiais: tetrassegmentados (0); bissegmentados (1). $(\mathrm{IC}=50 ; \mathrm{IR}=0)$. Caráter 1 de Kimsey (1987), 2 de Kimsey (1982) e 1 de Engel (1999)

Palpos labiais bissegmentados é a condição encontrada em
Aglae, Eulaema e na espécie de Exaerete examinada.

8. Pilosidade do mesossoma: muito densa (0); densa (1); escassa (2). (IC = 100; IR = 100). Caráter 12 de Kimsey (1982).

Mesossoma com pilosidade muito densa ocorre somente no grupo-externo; em Eufriesea e Eulaema ela é densa, permitindo ver difusamente o tegumento, já em Exaerete, Aglae e Euglossa é escassa permitindo ver completamente o tegumento.

9. Tubérculo hipoepimeral: ausente (0); presente (1). (IC = 100; IR = 100). Caráter 11 de Engel (1999).

Tubérculo hipoepimeral é encontrado apenas em Exaerete smaragdina (Guérin, 1845) e em outras duas espécies deste gênero.

10. Bordo posterior do mesoscuto: ligeiramente convexo (0); quase reto (1). $(\mathrm{IC}=100 ; \mathrm{IR}=100)$.

Em todos os Euglossini o bordo posterior do mesoscuto apresenta-se praticamente reto, uma sinapomorfia para todos os gêneros que compóem a tribo.

11. Linha mesoscutal: sulcada (0); saliente (1). (IC = 100; IR $=100)$.

A linha mesoscutal está disposta longitudinalmente nos $2 / 3$ anteriores do mesoscuto dividindo-o ao meio; em Eulaema ela é saliente ao passo que no demais Euglossini e no grupo externo ela é sulcada.

12. Escutelo visto de perfil: convexo (0); deprimido dorsoventralmente (1). (IC = 50; IR = 0). Caráter 3 de Kimsey (1987) e 2 de Engel (1999).

Apenas em Aglae e Eulaema, o escutelo tem um formato laminar, sendo bastante deprimido dorso-ventralmente.

13. Tufo de pêlos no escutelo das fêmeas: ausente (0); presente (1). (IC = 50; IR =0). Caráter 4 de Kimsey (1987) e 3 de Engel (1999).

Apenas fêmeas de Euglossa e Eulaema possuem um tufo de pêlos de formato navicular na porção mediano-posterior do escutelo. Em Euglossa mandibularis Friese, 1899, é comum também em machos (Peruquetti, 2002) e, em fêmeas de Euglossa atroveneta Dressler, 1978, chega a ser reduzidíssimo (G.A.R. Melo, com. pess.).

14. Bordo posterior do escutelo: ligeiramente convexo ou reto $(0)$; ligeiramente côncavo $(1) .(\mathrm{IC}=50 ; \mathrm{IR}=0)$.

Além de possuírem o escutelo deprimido dorso-ventralmente (caráter 12, acima), Eulaema e Aglae apresentam-no levemente côncavo posteriormente, sugerindo que esses dois estados surgiram simultaneamente.

15. Pente jugal das asas posteriores: ausente (0); presente (1). $(\mathrm{IC}=100 ; \mathrm{IR}=100)$. Caráter 15 de Engel (1999).

Em todos os gêneros de Euglossini e Bombini o lobo jugal é ausente, mas somente em Euglossini existe uma estrutura denominada pente jugal. 
16. Concavidade ventral do mesossoma: ausente (0); presente (1). $(I C=50 ; I R=50)$. Caráter 5 de Kimsey (1987) e 4 de Engel (1999).

Euglossa, Eufriesea e Exaerete possuem uma concavidade no mesossoma que abriga a glossa quando em repouso. A ausência desse sulco em Aglae e Eulaema foi interpretada por Kimsey (1987) como uma reversão e considerada derivada, apesar da autora reconhecer que essa era a condição encontrada no grupoexterno.

17. Lamela das tíbias médias: ausente (0); presente (1). (IC = 100; IR = 100). Caráter 5 de Engel (1999).

Engel (1999) chamou de carena essa expansão do tegumento na porção posterior da tíbia média e codificou-a como ausente (0), incompleta (1) e completa (2).

18. Aspecto da lamela da tíbia média: incompleta (0); completa (1). (IC = 50; IR = 0). Caráter 5 de Engel (1999).

19. Projeção apicolateral das tíbias médias: ausente (0); presente (1). (IC = 100; IR = 100). Caráter 8 de Kimsey (1987).

Como já tinha sido verificado por Kimsey (1987) todos os Euglossini, menos Aglae, possuem uma projeção apicolateral da tíbia média.

20. Dente na face interna dos basitarsos médios: ausente (0); presente (1). (IC = 100; IR = 100). Caráter 13 de Engel (1999).

Caráter de ocorrência exclusiva em Exaerete.

21. Dentição nos fêmures posteriores: ausente (0); presente (1). (IC = 100; IR = 100). Caráter 12 de Engel (1999).

Outro caráter de ocorrência exclusiva em Exaerete.

22. Fenda nas tíbias das pernas posteriores dos machos: ausente (0); presente (1). (IC = 100; IR = 100). Caráter 13-15 de Kimsey (1987) e 14 de Engel (1999).

23. Largura da fenda: ampla e ovóide (0); estreita e curva (1). (IC = 100; IR = 100). Caráter 13-15 de Kimsey (1987) e 6 de Engel (1999).

É na fenda tibial que os machos de Euglossini depositam as substâncias aromáticas que coletam. Em Eufriesea e Eulaema ela é ampla e ovóide, ao passo que em Euglossa, Exaerete e Aglae é estreita e curva na base. Kimsey (1987) e Engel (1999) consideraram Aglae no estado (0).

24. Comprimento da fenda tibial: atingindo o ápice (0); não atingindo (1). $(\mathrm{IC}=50 ; \mathrm{IR}=0)$. Caráter 5 de Kimsey (1987) e 7 de Engel (1999).

Em Euglossa e Aglae a fenda não atinge o ápice da tíbia, ao contrário de Eulaema, Eufriesea e Exaerete smaragdina. Kimsey (1987) e Engel (1999) consideraram que em Aglae a fenda tibial alcança o ápice da tíbia.

25. Bordo posterior do ápice das tíbias posteriores: arredondado (0); pontiagudo (1). (IC = 100; IR = 100). Caráter 8 de Engel (1999).
No grupo-externo, em Euglossa, Exaerete e Aglae, o bordo posterior da tíbia posterior possui aspecto arredondado, ao passo que em Eulaema e Eufriesea ele é pontiagudo.

26. Pilosidade na face externa das tíbias posteriores: densa (0); pouco densa (1); escassa (2). ( IC = 100; IR = 100).

$\mathrm{Na}$ face externa das tíbias posteriores do grupo-externo a pilosidade é densa; em Eufriesea e Eulaema é pouco densa, permitindo ver difusamente o tegumento; já em Exaerete, Aglae e Euglossa é escassa, permitindo ver completamente o tegumento.

27. Corbícula: desenvolvida (0); muito reduzida ou quase nula (1). (IC = 50; IR =0). Caráter 4 de Kimsey (1987).

Nos gêneros cleptoparasíticos, Aglae e Exaerete, a corbícula é bastante reduzida.

28. Comprimento das tíbias das pernas posteriores: longa, mais de duas vezes a largura (0) curta, menos de duas vezes (1). $(\mathrm{IC}=100 ; \mathrm{IR}=100)$. Caráter 6 de Kimsey (1982).

No grupo-externo, em Aglae e Exaerete as tíbias posteriores são muito longas, ao contrário dos demais Euglossini.

29. Comprimento do quinto tarsômero das pernas posteriores: igual ao da perna média (0); menor (1); maior (2). $(\mathrm{IC}=100 ; \mathrm{IR}=100)$.

Euglossa e Exaerete possuem o quinto tarsômero das pernas posteriores maiores que seus equivalentes das pernas médias, enquanto Eulaema e Eufriesea possuem-no menor. Em Aglae eles se apresentam do mesmo tamanho, como no grupo-externo.

30. Comprimento dos esporóes das tíbias das pernas posteriores: externo menor que o interno (0); quase iguais (1). $(\mathrm{IC}=100 ; \mathrm{IR}=100)$.

Apis e Melipona não possuem esporões, mas em Bombus o externo é menor que o interno, assim como Aglae, Euglossa e Exaerete. Em Eufriesea e Eulaema eles são aproximadamente do mesmo tamanho.

31. Bordo ântero-superior do primeiro tergo: levemente côncavo ou reto (0); projetado anteriormente (1). (IC = 100; IR $=100)$.

Em Aglae o primeiro tergo possui o bordo projetado anteriormente, uma autapomorfia, diferentemente dos demais Euglossini e do grupo-externo, onde ele é levemente côncavo ou reto.

32. Comprimento da porção dorsal do primeiro tergo: cerca de metade do segundo (0); cerca de um terço (1). (IC = 100; IR $=100)$.

Somente Eulaema apresenta o primeiro tergo com comprimento que equivale a cerca de $1 / 3$ do segundo, portanto uma autapormorfia para esse gênero.

33. Tufos de pêlos no segundo esterno: ausentes (0); presentes (1). (IC = 100; IR = 100). Caráter 17 de Kimsey (1987). 
Tufos de pêlos no segundo esterno é exclusividade de Euglossa, embora possa faltar em algumas espécies do subgênero Glossurella.

34. Lobo apical do oitavo esterno em perfil: deprimido dorsoventralmente (0); expandido (1). ( $I C=100 ; \mathrm{IR}=100)$.

35. Projeção ventro-lateral do gonocoxito: ausente (0); presente (1). $(I C=100 ; I R=100)$. Caráter 19 de Kimsey (1987) e 9 de Engel (1999).

36. Aurícula: ausente (0); presente (1). $(\mathrm{IC}=66 ; \mathrm{IR}=0)$

Fêmeas de Euglossini possuem uma estrutura denominada aurícula, que é uma franja de pêlos curtos e eretos na base do basitarso da perna posterior, a qual pode desempenhar algum papel no transporte do pólen (Michener et al. 1978). Essa estrutura não é encontrada no grupo-externo.

37. Gonóstilos: simples (0); bilobado (1). ( $(\mathrm{C}=100 ; \mathrm{IR}=$ 100). Caráter 10 de Kimsey (1982).

\section{MONOFILIA DE EULAEMA E RELACIONAMENTOS FILOGENÉTICOS} ENTRE AS ESPÉCIES

\section{Seleção dos caracteres}

$\mathrm{Na}$ análise das relaçôes entre as espécies de Eulaema, a maioria dos caracteres escolhidos são originais, com exceção do número 20 de Ospina-Torres (1998) e os de números 1, 3, 4, 9, 10 e 12 de Moure (1950). Para enraizamento das árvores foram utilizados como grupo-externo machos de Eufriesea surinamensis (Linnaeus, 1758) e Euglossa augaspis Dressler, 1982. As autapomorfias não foram incluídas.

\section{CARACTERES ESTUDADOS}

1-Manchas amarelo-esbranquiçadas na face: $0=$ ausentes; $1=$ presentes. $(I C=100 ; \mathrm{IR}=100)$.

Esse foi um dos caracteres utilizados por Moure (1950) para distinguir os subgêneros Eulaema e Apeulaema. Machos das espécies pertencentes a esse último subgênero $(E$. nigrita Lepeletier, 1841, E. mocsaryi (Friese, 1899), E. cingulata (Fabricius, 1804), E. polychroma (Mocsáry, 1899), E. boliviensis (Friese, 1898) e E. pseudocingulata Oliveira, 2006), geralmente apresentam algumas manchas ou estrias amarelo-esbranquiçadas ao longo do clípeo e áreas paraoculares, ou mesmo na margem do clípeo e na área supraclipeal. Entretanto, esse caráter, às vezes, pode faltar totalmente, sendo que pelo menos um macho de $E$. parapolyzona Oliveira, 2006 (subgênero Eulaema) apresentava manchas na face. Euglossa, de um modo geral apresenta estrias amarelo-esbranquiçadas nas áreas paraoculares. Entretanto, como tais manchas não ocorrem em Eufriesea, essa condição foi presumida como plesiomórfica.

2-Base da sutura epistomal em vista frontal: $0=$ curva; $1=$ reta. $(\mathrm{IC}=33 ; \mathrm{IR}=66)$.

Sutura epistomal curva é a condição encontrada no grupoexterno e também em algumas espécies pertencentes ao grupo meriana dentro do subgênero Eulaema: E. flavescens (Friese,
1899); E. terminata Smith, 1874; E. meriana (Olivier, 1789); e E. bombiformis (Packard, 1869).

3-Comprimento do clípeo: $0=$ menor que a distância interorbital; $1=$ maior. $(\mathrm{IC}=100 ; \mathrm{IR}=100)$.

Também utilizada por Moure (1950). Clípeo curto é a condição encontrada no grupo-externo e em todos os representantes do subgênero Apeulaema.

4-Comprimento da área malar: $0=$ menor que o diâmetro do terceiro flagelômero (Fig. 1b,c); $1=$ maior (Fig. 1a). (IC = 100; $\mathrm{IR}=100)$.

Outra característica utilizada por Moure (1950), sendo que a área malar maior que o diâmetro do terceiro flagelômero é a condição encontrada em todas as espécies do grupo meriana.

5-Ápice do clípeo em vista frontal: $0=$ reto; $1=$ curvo. $(\mathrm{IC}=$ 100 ; $\mathrm{IR}=100$ ).

Ápice do clípeo curvo, ocorre no grupo polyzona: E. polyzona Mocsáry, 1897 e E. parapolyzona e subgrupo leucopyga: $E$. bennetti Moure, 1967; E. luteola Moure, 1967; E. tenuifasciata (Friese, 1925); E. seabrai Moure, 1960; E. leucopyga (Friese, 1898); E. bomboides (Friese, 1923) e E. helvola Moure, 2000.

6-Projeção dentiforme interna da área genal: $0=$ ausente; $1=$ moderada; $2=$ pronunciada. $(\mathrm{IC}=66 ; \mathrm{IR}=93)$.

As espécies pertencentes ao subgrupo leucopyga possuem uma projeção dentiforme moderada situada internamente na área genal, enquanto em todas as espécies do subgênero Apeulaema mais as espécies do grupo speciosa ela é bastante pronunciada: $E$. speciosa (Mocsáry, 1897); E. nigrifacies (Friese, 1898) e E. napensis Oliveira, 2006 e grupo peruviana: E. peruviana (Friese, 1903) e E. basicincta Moure, 2000. No grupo-externo e nas demais espécies de Eulaema, não existe tal projeção.

7-Projeção dentiforme inferior da área malar: $0=$ ausente (Fig. 1b); 1 = aguda (Fig. 1c); $2=$ rombuda (Fig. 1a). (IC = 66; IR = 88).

Em todas as espécies de Apeulaema, a área malar possui uma projeção dentiforme aguda, enquanto nas espécies pertencentes
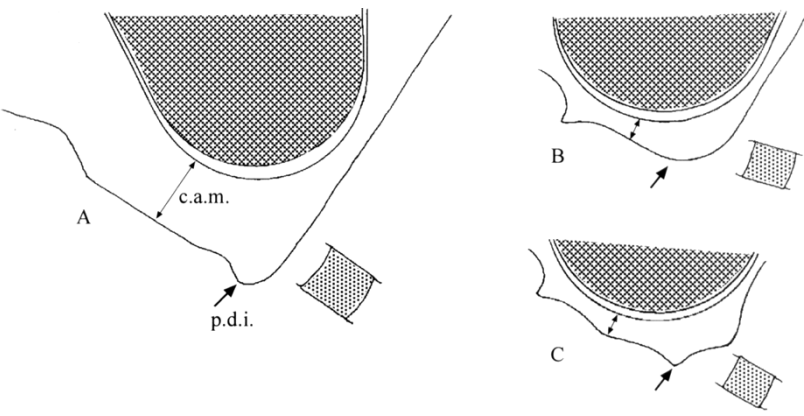

$1 \mathrm{~mm}$

Figura 1 - Área malar. $\mathrm{A}=$ E. meriana, $\mathrm{B}=E$. polyzona, $\mathrm{C}=$ E. polychroma c.a.m = comprimento da área malar; p.d.i = projeção dentiforme inferior À diretia, o $3^{\circ}$ flagelômero. 
ao grupo meriana ela é rombuda, com exceção de E. bombiformis, que não possui essa projeção. Essa projeção está ausente também no grupo-externo e nas demais espécies do subgênero Eulaema.

8-Padrão de coloração das asas anteriores: $0=$ âmbar e transparente; $1=$ metade basal enegrecida e ápice âmbar transparente. ( $I C=50 ; \mathrm{IR}=88$ ).

Asas anteriores âmbar e transparentes são encontradas no grupo-externo, em Apeulaema, com exceção de E. nigrita que apresenta as asas bastante enegrecidas e ainda no grupo speciosa (subgênero Eulaema).

9-Comprimento da área aveludada da tíbia média: $0=$ muito longa (Fig. 2d, g); $1=$ longa (Fig. 2c, e, f); $2=$ curta (Fig. 2a, i); $3=$ muito curta (Fig. 2b). $(I C=100 ; I R=100)$.

Moure (1950) já tinha chamado a atenção para a forma dessa área situada na face externa das tíbias médias, cuja função é ainda desconhecida e que tem sido denominada de área aveludada. No grupo-externo e em todos os representantes do subgênero Apeulaema, mais os grupos speciosa e peruviana, a área aveludada é muito longa. No subgrupo leucopyga, é curta, com exceção de E. leucopyga e E. bomboides, onde ela é muito curta.

10-Largura da área aveludada: $0=$ estreita (Fig. 2e, f, h); $1=$ muito estreita (Fig. 2c, i); $2=$ ampla (Fig. 2a, b); 3= muito ampla (Fig. 2d, g). (IC = 60; IR = 88).

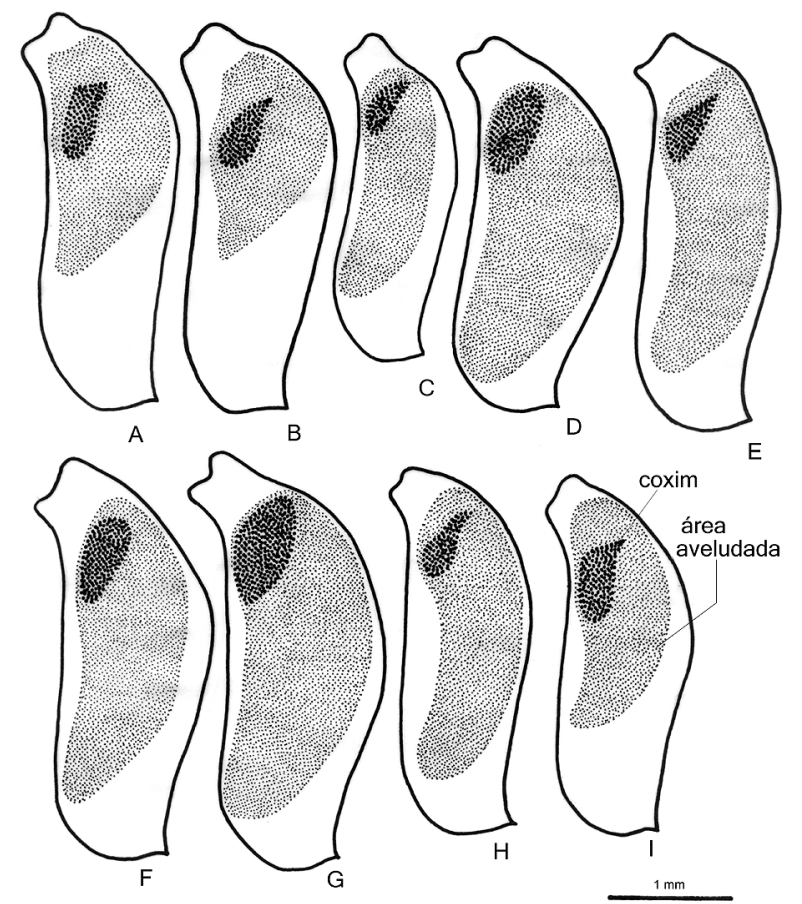

Figura 2 - Área aveludada. $\mathrm{A}=$ E. leucopyga, $\mathrm{B}=$ E. bomboides, $\mathrm{C}=E$. polychroma, $\mathrm{D}=$ E. boliviensis, $\mathrm{E}=$ E. napensis, $\mathrm{F}=$ E. pseudocingulata, $\mathrm{G}$ $=E$. cingulata, $\mathrm{H}=E$. parapolyzona, $\mathrm{I}=E$. polyzona.
Em Euglossa e no subgrupo leucopyga, a área aveludada é ampla, mas em Eufriesea é estreita, assim como nos grupos polyzona, peruviana e speciosa.

11-Largura da região subapical da fenda tibial: $0=$ mais estreita que a base (Fig. 3a); $1=$ da mesma largura (Fig. 3b); $2=$ mais larga (Fig. 3c). ( $I C=100 ; I R=100)$.

A região subapical da fenda localizada nas tíbias posteriores é da mesma largura que a base no grupo peruviana (1) e mais larga no grupo polyzona (2).

12-Comprimento dos pêlos do basitarso da tíbia posterior: $0=$ tão longos quanto a maior largura do basitarso; $1=$ um pouco mais longos; $2=$ duas vezes mais longos. $(\mathrm{IC}=100 ; \mathrm{IR}=100)$.

Os pêlos situados no bordo posterior dos basitarsos posteriores possuem comprimento igual à largura dos basitarsos nas espécies do subgênero Apeulaema e nas espécies dos grupos speciosa e peruviana. Essa é a condição que ocorre no grupo-externo.

13-Bordo posterior do sexto tergo metassomático: $0=$ levemente arredondado; $1=$ com projeção no meio. $(\mathrm{IC}=100$; $\mathrm{IR}=100)$.

O bordo posterior do sexto tergo metassomático é levemente projetado no meio e ocorre apenas nas espécies do grupo meriana.

14-Bordo posterior do quinto esterno: $0=$ relativamente reto e sem reentrâncias (Fig. 4c); 1 = arredondado e com duas leves reentrâncias (Fig. 4b); 2 = relativamente arredondado e sem reentrâncias (Fig. 4a); 3= com uma forte reentrância no meio (Fig. 4d); $4=$ com duas profundas reentrâncias nas laterais (Fig. 4e); $5=$ com duas leves reentrâncias nos cantos (Fig. 4f); 6= com três fortes reentrâncias (Fig. 4g). ( $\mathrm{IR}=66 ; \mathrm{IR}=78)$
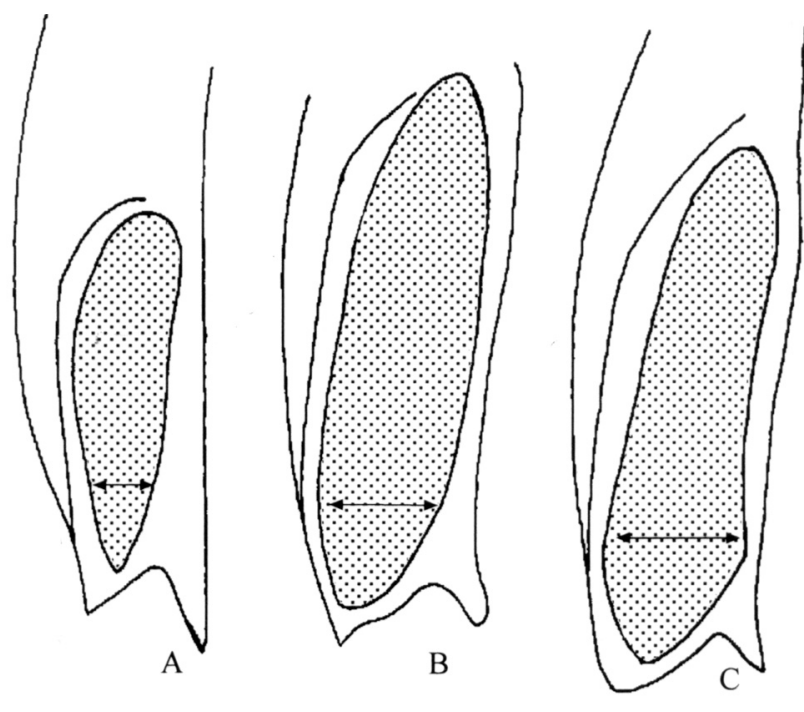

$1 \mathrm{~mm}$

Figura 3 - Fenda tibial. $\mathrm{A}=$ E. polychroma, $\mathrm{B}=$ E. peruviana, $\mathrm{C}=\mathrm{E}$. parapolyzona 

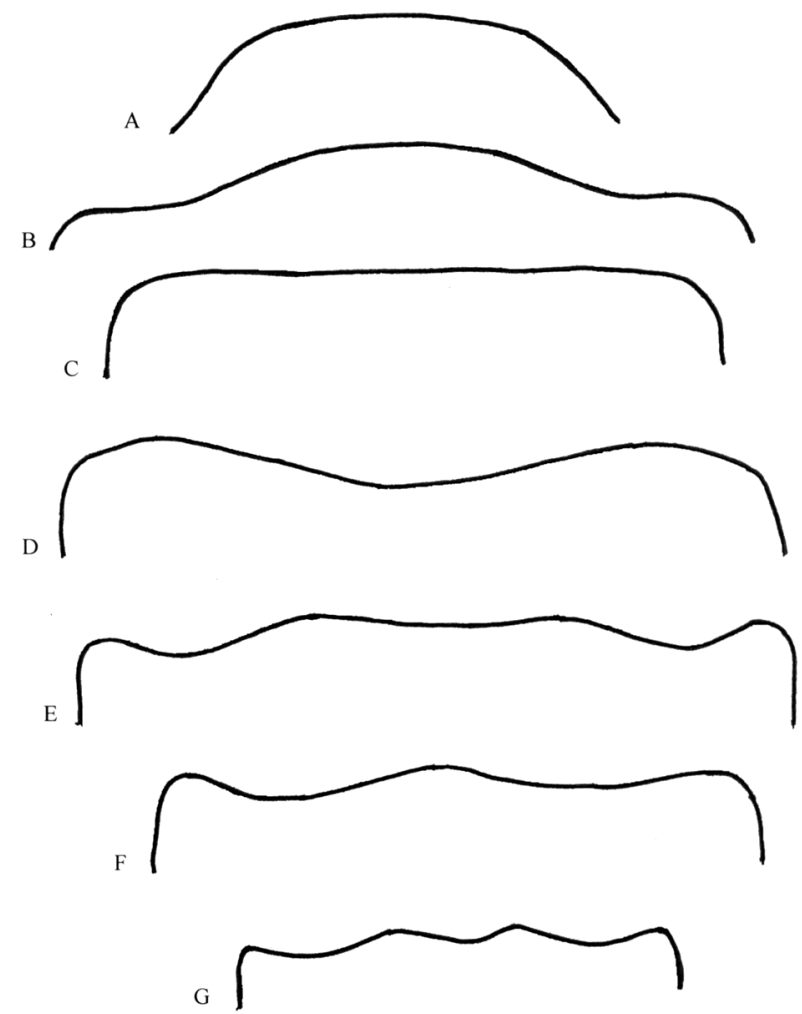

$1 \mathrm{~mm}$

Figura 4 - Bordo posterior do quinto esterno. $\mathrm{A}=$ E. pseudocingulata, $\mathrm{B}=$ E. polyzona, $\mathrm{C}=E$. sororia, $\mathrm{D}=E$. flavescens, $\mathrm{E}=E$. helvola, $\mathrm{F}=E$. bennetti, $\mathrm{G}=E$. tenuifasciata.

No grupo-externo e em E. sororia Dressler \& Ospina-Torres, 1997 E. chocoana Ospina-Torre \& Sandino-Franco, 1997 e E. leucopyga o bordo posterior do quinto esterno é relativamente reto e sem reentrâncias

15-Pilosidade do quinto esterno: $0=$ fina e amplamente distribuída; 1 = fina e restrita a uma fileira no bordo posterior; $2=$ muito fina e reduzida a uma fileira no bordo posterior; $3=$ ausente. $(\mathrm{IC}=100 ; \mathrm{IR}=100)$.

Pilosidade fina e amplamente distribuída é a condição verificada no grupo-externo, nas espécies do subgênero Apeulaema e ainda nos grupos speciosa e peruviana e em apenas três espécies do grupo meriana (E. sororia, E. chocoana e E. bombiformis).

16-Local de inserção da fileira de pêlos no bordo posterior do quinto esterno: $0=$ distante do bordo; $1=$ muito próximo. (IC = 100; IR = 100).

Apenas nas espécies do grupo polyzona e em três do grupo meriana (E. flavescens, E. terminata e E. meriana), a pilosidade do quinto esterno está reduzida a uma fileira de pêlos. A posição distante do bordo foi considerada plesiomórfica. Nas demais espécies, a pilosidade do quinto esterno está ausente ou amplamente distribuída.
17-Braços do quinto esterno: $0=$ curtos e muito abertos (Fig. 5a); 1 = curtos e pouco abertos (Fig. 5b); $2=$ longos e pouco abertos (Fig. 5c); 3= longos e fechados (Fig. 5d); 4= longos e abertos (Fig. 5e); $5=$ muito longos e abertos (Fig. 5f); $6=$ muito longos e pouco arqueados (Fig. 5g); $7=$ muito longos e arqueados (Fig. 5h). (IC = 87; IR =92).

Os braços do sétimo esterno são bastante variáveis na forma e tamanho. São curtos e muito abertos no grupo-externo e também nas espécies dos grupos polychroma (E. pseudocingulata e $E$. polychroma), peruviana (E. peruviana e E. basicincta) e ainda parte do grupo speciosa (E. nigrifacies e E. speciosa).

18-Saliências nos braços do sétimo esterno: $0=$ ausentes (Fig. 5a-h); $1=$ presentes (Fig. $5 \mathrm{i})$. (IC = 100; IR = 100).

Somente nas espécies do grupo peruviana os braços do sétimo esterno apresentam saliências, uma provável apomorfia para esse grupo.

19-Entalhes nos braços do sétimo esterno: $0=$ ausentes (Fig. 5a-f, i); $1=$ com um entalhe raso (Fig. $5 \mathrm{~g}$ ); $2=$ com um entalhe profundo (Fig. 5h). (IC = 100; IR = 100).

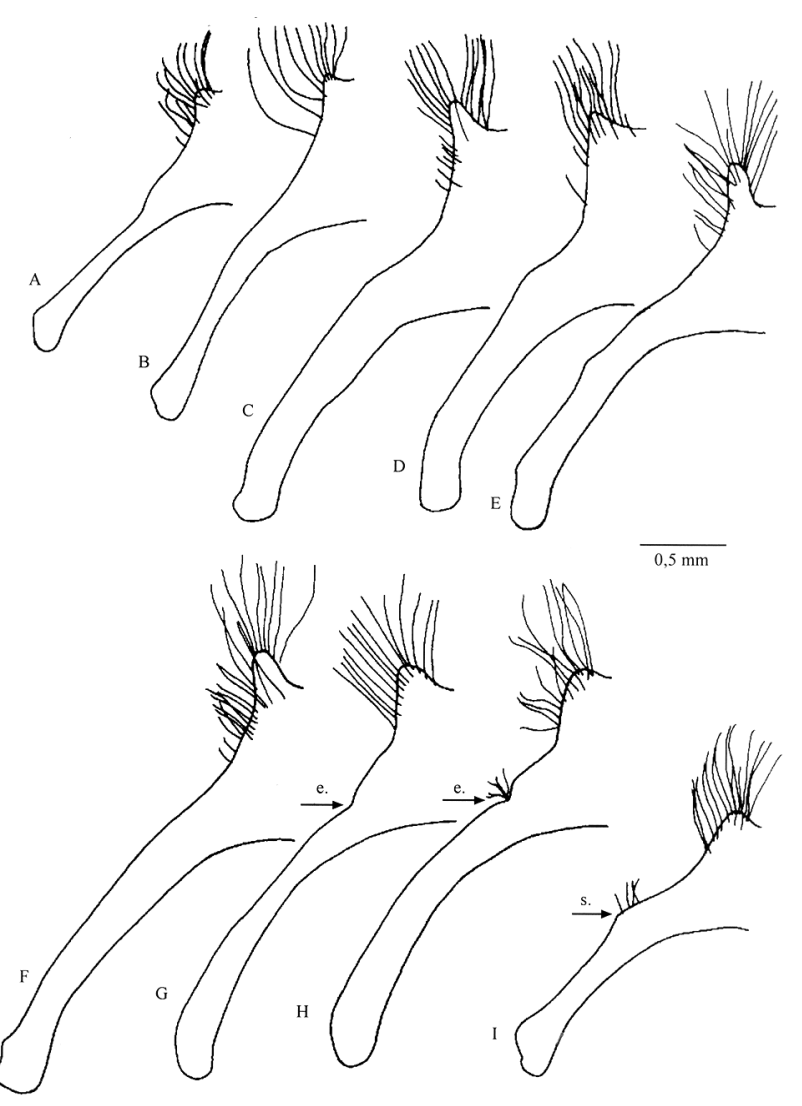

Figura 5 - Sétimo esterno. $\mathrm{A}=E$. polychroma, $\mathrm{B}=$ E. cingulata, $\mathrm{C}=E$. flavescens, $\mathrm{D}=$ E. terminata, $\mathrm{E}=\mathrm{E}$. chocoana, $\mathrm{F}=$ E. bombiformis, $\mathrm{G}=$ E. bennetti, $\mathrm{H}=E$. luteola, $\mathrm{I}=E$. basicincta. $\mathrm{e}=$ entalhe; $\mathrm{s}=$ saliência. 
O clado $E$. luteola-E. helvola apresenta um entalhe raso nos braços do sétimo esterno, enquanto o clado $E$. bennetti-E. tenuifasciata-E. seabrai apresenta um entalhe profundo, constuindo prováveis apomorfias para esses dois grupos.

20-Projeção lateral do oitavo esterno: $0=$ ausente (Fig. 6b); $1=$ curta e arredondada (Fig. 6a); $2=$ curta e pontiaguda (Fig. 6c); $3=$ longa e pontiaguda (Fig. 6d). (IC = 60; IR = 80).

Ospina-Torres (1998) já tinha chamado a atenção para essa peculiaridade do oitavo esterno dos machos. Entretanto, além do grupo-externo, ela está ausente nas espécies dos grupos nigrita, polyzona e leucopyga.

21-Comprimento dos gonóstilos: $0=$ curtos e com extremidade muito larga (Fig. 7c); $1=$ curtos e moderadamente largos (Fig. 7a); 2 = curtos e com extremidade estreita (Fig. 7b); $3=$ longos e com extremidade moderadamente larga (Fig. 7d); $4=$ longos e com extremidade estreita (Fig. 7e); $5=$ longos e com base muito larga (Fig. 7f); $6=$ moderadamente longos e com ponta estreita (Fig. 7g). $(I C=100 ; \mathrm{IR}=100)$.

Em Euglossa, os gonóstilos são curtos e possuem a extremidade muito larga, como nas espécies do grupo polyzona. Entretanto, em Eufriesea eles são longos e bilobados o que não é encontrado nos demais Euglossini. A condição existente em Euglossa foi presumida como plesiomórfica.

22-Coloração dos tegumentos dos tergos metassomáticos: 0 = metálicos ou com reflexos metálicos; $1=$ pretos e sem esses reflexos. $(I C=100 ; \mathrm{IR}=100)$.

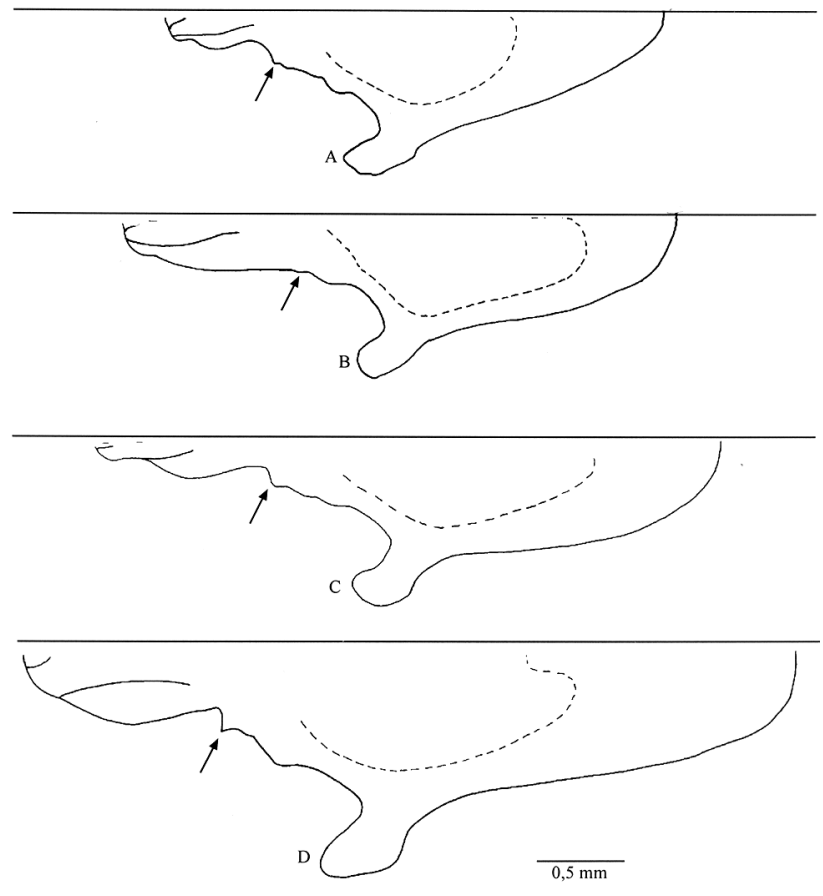

Figura 6 - Projeção lateral do oitavo esterno. $\mathrm{A}=$ E. basicincta, $\mathrm{B}=E$. nigrita, $\mathrm{C}=$ E. pseudocingulata, $\mathrm{D}=\mathrm{E}$. flavescens.

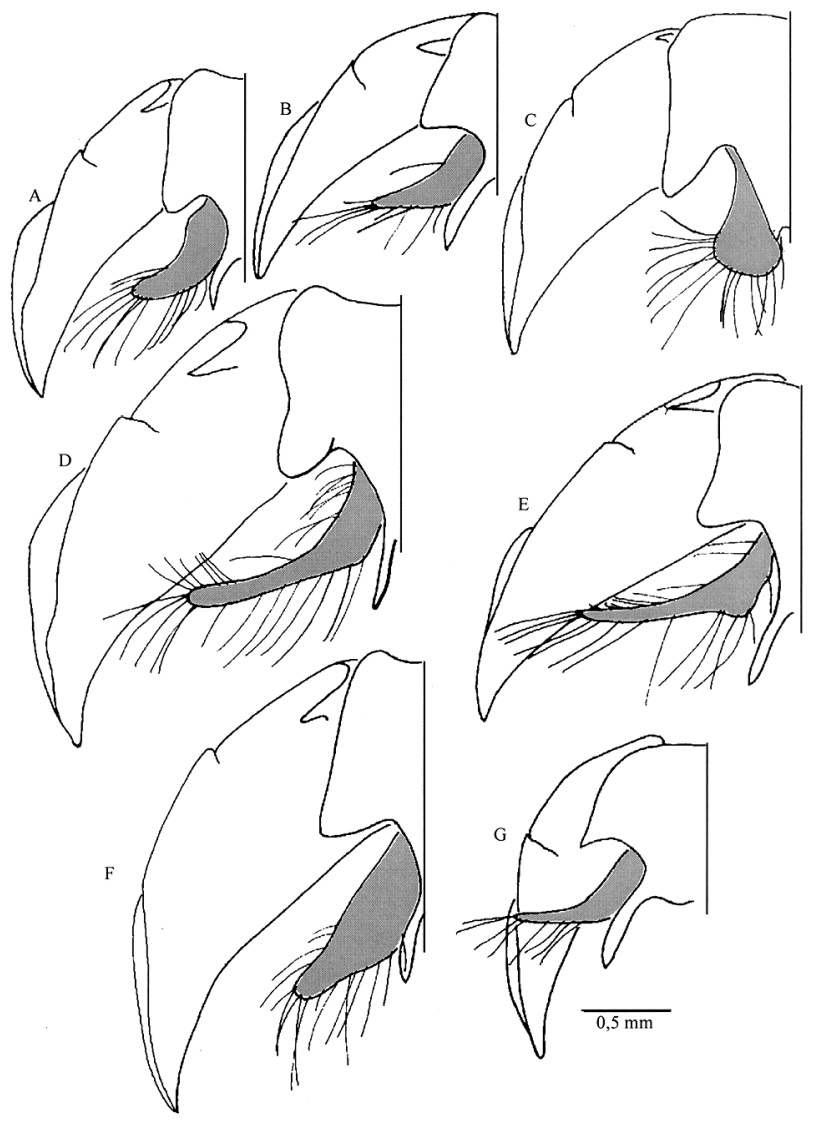

Figura 7 - Forma do gonóstilo. $\mathrm{A}=E$. napensis, $\mathrm{B}=E$. pseudocingulata, $\mathrm{C}=E$. parapolyzona, $\mathrm{D}=E$. bombiformis, $\mathrm{E}=E$. chocoana, $\mathrm{F}=E$. bomboides, $\mathrm{G}=E$. peruviana.

Quando propôs a divisão de Eulaema em dois subgêneros, Moure (1950) usou, entre outras coisas, essa característica do brilho metálico do tegumento. Eulaema s. str. possui forte brilho metálico nos tergos metassomáticos anteriores e fraco nos posteriores, enquanto Apeulaema, não possui esse brilho, ou o mesmo encontra-se reduzido a alguns reflexos nos últimos tergos em E. nigrita.

\section{RESULTADOS E DISCUSSÃO}

\section{RELACIONAMENTOS FILOGENÉTICOS ENTRE OS GÊNEROS DE EUGLOSSINI E MONOFILIA DE EULAEMA}

De acordo com os resultados aqui obtidos (Fig. 8), o gênero Eulaema tem seu monofiletismo suportado por quatro apomorfias: projeção genal (caráter 5), clípeo bastante elevado e com rampas íngremes lateralmente (caráter 6), linha mesoscutal saliente (caráter 11) e tergo I medindo cerca de $1 / 3$ do comprimento do tergo II (caráter 32). Entretanto, projeção genal precisa ser vista com uma certa reserva, já que estrutura semelhante ocorre em Euglossa intersecta Latreille, 1938 e, conforme se 
verificou recentemente, em Paleoeuglossa melissiflora Poinar, 1999, fóssil de Euglossini descoberto em âmbar na Republica Dominicana (Poinar, 1999).

A primeira hipótese de filogenia para os gêneros de Euglossini apareceu em Kimsey (1982) (Fig. 10-a). A autora apresentou como autapomorfia para Eulaema, apenas o caráter 'palpo labial bissegmentado'. Um dos problemas com essa hipótese de filogenia, é que esse mesmo caráter aparece, no cladograma elaborado pela autora, unindo Euglossa e Exaerete, o que constituiria uma homoplasia. Mas isso certamente deve ter sido um equívoco da autora, uma vez que palpo labial bissegmentado não ocorre em Euglossa, nem em três das cinco espécies de Exaerete, mas ocorre em Aglae, o que foi omitido.

Posteriormente, Kimsey (1987) apresentou uma outra hipótese de filogenia para os gêneros de Euglossini (Fig. 10-b). Nesse cladograma, Eulaema aparece sustentada por dois caracteres: projeção genal, já comentado anteriormente, e tufo escutelar nas fêmeas, também homoplástico, ocorrendo em fêmeas de todas as espécies de Euglossa.

Engel (1999) apresentou uma terceira hipótese de filogenia para os gêneros de Euglossini (Fig. 10-d) onde três sinapomorfias sustentam Eulaema: tufo escutelar nas fêmeas; tíbia posterior dos machos com margem apical pontiaguda e presença de projeção gonocoxal na cápsula genital dos machos. Tanto o segundo quanto o terceiro caráter ocorrem, independentemente, em Eufriesea.

De acordo com os resultados aqui apresentados, Eufriesea seria o principal candidato a irmão de Eulaema, enquanto Aglae seria o grupo-irmão dos demais gêneros de Euglossini. Seis

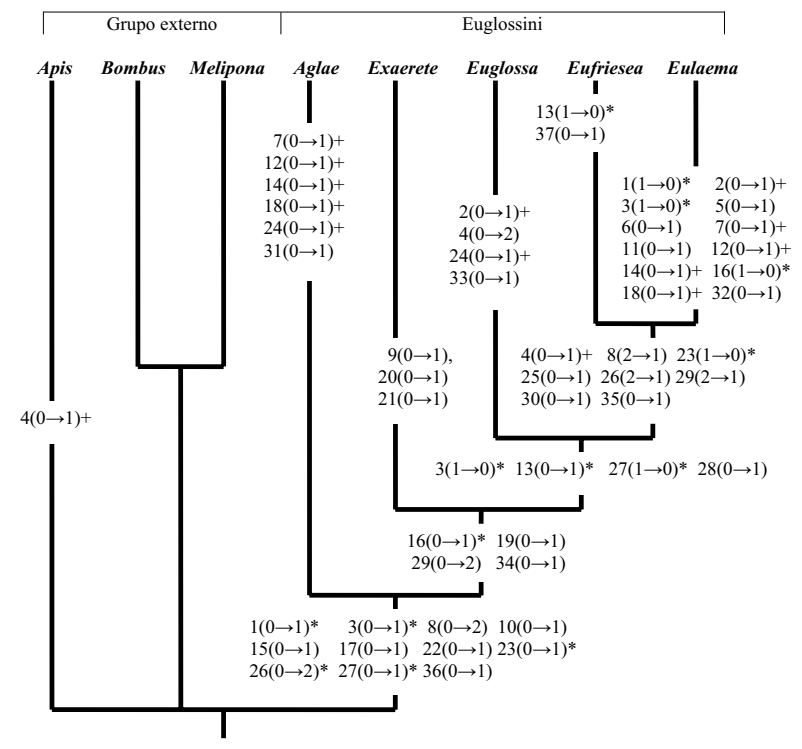

Figura 8 - Cladograma para os gêneros de Euglossini (comprimento 56 passos, IC $=75$ e IR $=69$ ). $+=$ homoplasia, ${ }^{*}=$ reversão ou perda. sinapomorfias sustentando o clado Eulaema-Eufriesea: tórax com pilosidade densa, face externa das tíbias posteriores com pilosidade pouco densa, tíbias posteriores dos machos com ápice pontiagudo, quinto tarsômero das pernas posteriores menores que os das pernas médias, esporões internos e externos das tíbias posteriores aproximadamente iguais no tamanho e gonocoxito com projeção ventro-lateral. O caráter 'fenda das tíbias posteriores ampla e ovóide" também poderia constituir uma sinapomorfia, se a polarização adotada fosse outra. O clado Eulaema-Eufriesea já havia sido proposto por Kimsey (1982), somente com uma autapomorfia sustentando-o: "gonocoxa with a ventral lobe [of gonostylus]". Essa referência ao gonóstilo feita pela autora e sua colocação como autapomorfia para Euglossa, não fazem sentido. Esse caráter deve corresponder ao 'gonocoxito com projeção ventro-lateral' aqui estudado e ainda a 'gonocoxal projection' de Engel (1999) e não ao 'gonóstilo bilobado' também aqui estudado, que é uma autapomorfia de Eufriesea. Ao que tudo indica, essas correçōes foram feitas pela autora posteriormente, pois afirma: "Lobate gonocoxa. In Euglossa, Exaerete and Aglae the ventral margin of the gonocoxa viewed laterally is simple. Eufriesea and Eulaema have a long digitate projection ventrally, adjacent to but no connected to the gonostylus" (Kimsey, 1987). Entretanto, no cladograma apresentado, esse caráter se encontra uma vez no ancestral de Eufriesea-Eulaema-Aglae, outra no ramo de Eufriesea e não há qualquer indicação de sua reversão em Aglae, o que contradiz o que foi dito acima pela autora.

Por outro lado, tanto no cladograma obtido por Kimsey (1987) quanto no de Engel (1999), Aglae forma um clado com Eulaema. Em Kimsey (op. cit.), o clado é sustentado por quatro sinapomorfias: palpo labial bissegmentado; escutelo achatado dorso-ventralmente; carena do bordo posterior das tíbias médias terminando junto ao ápice e ausência da concavidade ventral do mesossoma. Em Engel (1999), apenas os três primeiros caracteres sustentam o referido clado, já que o último caráter foi considerado plesiomórfico. O caráter 'palpo labial bissegmentado' utilizado por esses dois autores já recebeu comentários anteriormente. Quanto ao caráter 'ausência de sulco esternal', penso que Engel (1999) tem razão em considerá-lo como plesiomórfico. O caráter 'carena do bordo posterior das tíbias médias' utilizado por Kimsey (1987) parece ocorrer também nos demais Euglossini, tanto que Engel (1999) interpretou esse caráter como possuidor de dois estados: completo no clado Aglae-Eulaema e incompleto nos demais gêneros, o que foi considerado neste trabalho. Assim, restariam somente os caracteres 'escutelo achatado dorsoventralmente' e 'carena completa do bordo posterior das tíbias médias' sustentando o clado Eulaema-Aglae na proposta de Engel (1999) e apenas o primeiro caráter na de Kimsey (1987). Nos resultados aqui apresentados, esses dois caracteres têm origem independente.

A diferença entre as duas filogenias de Kimsey $(1982,1987)$, conforme já tinha sido observado por Michener (1990), é que 
no primeiro cladograma, Aglae aparece na base, como irmã dos demais gêneros e, no segundo, como irmã apenas de Eulaema. Michener (op. cit.) atribuiu essa mudança a uma inversão na polarização do caráter 'forma do esterno VIII nos machos' (caráter 7 no cladograma de Kimsey, 1982 e caráter 18 no de Kimsey, 1987). No entanto, a inversão mencionada não foi com esse caráter mas sim com o 'aspecto das válvulas peniais' (caráter 11 em Kimsey, 1982 e caráter 20 em Kimsey, 1987). Assim, o que

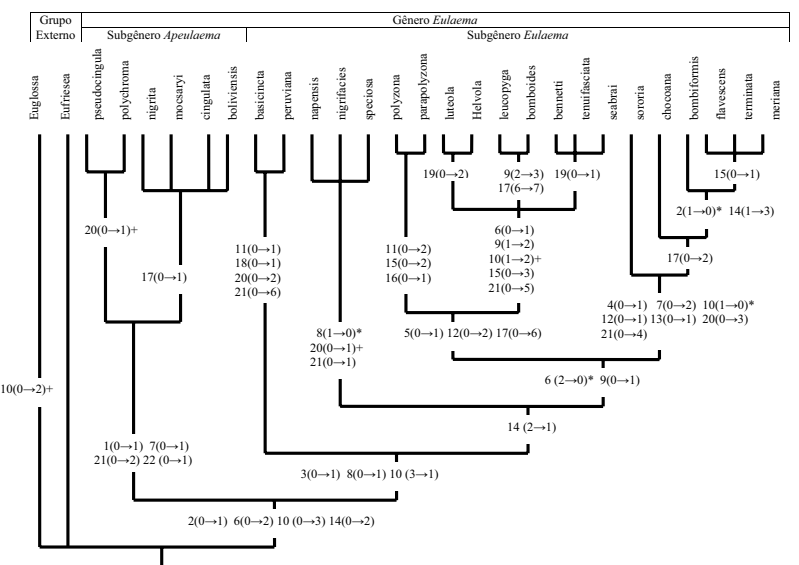

Figura 9 - Cladograma para as espécies de Eulaema. (comprimento $=67$ passos, IC $=79, I R=92$ ). $\quad+=$ homoplasia, ${ }^{*}=$ reversão ou perda. Autapomorfias não foram incluídas.

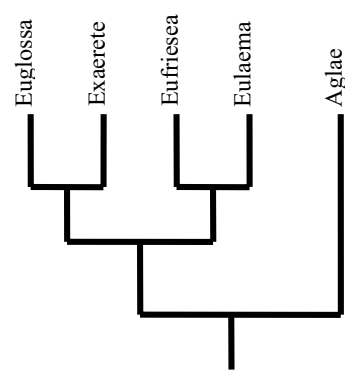

a) Kimsey (1982)

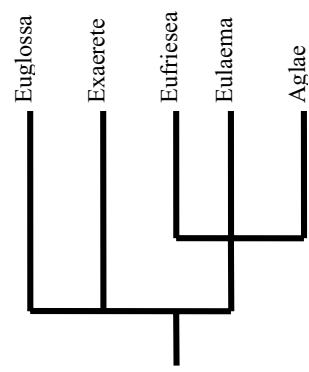

c) Michener (1990)

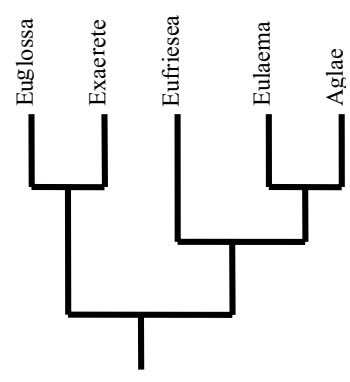

b) Kimsey (1987)

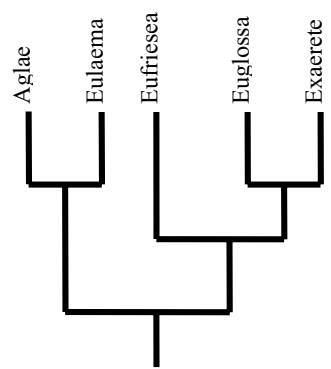

d) Engel (1999)
Figura 10 - Hipóteses de filogenia para a tribo Euglossini apresentadas por outros autores.

Tabela 1 - Matriz de dados para os gêneros de Euglossini e grupos externos.

\begin{tabular}{|c|c|c|c|c|c|c|c|c|c|c|c|c|c|c|c|c|c|c|c|c|c|c|c|c|c|c|c|c|c|c|c|c|c|c|c|c|c|}
\hline \multirow{2}{*}{ Espécies } & \multicolumn{37}{|c|}{ Caracteres } \\
\hline & 1 & 2 & 3 & 4 & 5 & 6 & 7 & 8 & 9 & 10 & 1 & 2 & 3 & 4 & 5 & 6 & 7 & 8 & 9 & 20 & 1 & 2 & 3 & 4 & 5 & 6 & 7 & 8 & 9 & 30 & 1 & 2 & 3 & 4 & 5 & 6 & 7 \\
\hline $\begin{array}{l}\text { Apis m. scutellata } \\
\text { Lepeletier, } 1836\end{array}$ & 0 & 0 & 0 & 1 & 0 & 0 & 0 & 0 & 0 & 0 & 0 & 0 & 0 & 0 & 0 & 0 & 0 & $?$ & 0 & 0 & 0 & 0 & $?$ & $?$ & 0 & 0 & 0 & 0 & 0 & $?$ & 0 & 0 & 0 & 0 & 0 & 0 & 0 \\
\hline $\begin{array}{l}\text { Bombus atratus } \\
\text { Franklin, } 1913\end{array}$ & 0 & 0 & 0 & 0 & 0 & 0 & 0 & 0 & 0 & 0 & 0 & 0 & 0 & 0 & 0 & 0 & 0 & $?$ & 0 & 0 & 0 & 0 & $?$ & $?$ & 0 & 0 & 0 & 0 & 0 & 0 & 0 & 0 & 0 & 0 & 0 & 0 & 0 \\
\hline $\begin{array}{l}\text { Melipona scutellaris } \\
\text { Latreille, } 1811\end{array}$ & 0 & 0 & 0 & 0 & 0 & 0 & 0 & 0 & 0 & 0 & 0 & 0 & 0 & 0 & 0 & 0 & 0 & $?$ & 0 & 0 & 0 & 0 & $?$ & $?$ & 0 & 0 & 0 & 0 & 0 & $?$ & 0 & 0 & 0 & 0 & 0 & 0 & 0 \\
\hline $\begin{array}{l}\text { Aglae caerulea } \\
\text { Lepeletier \& Serville, } 1825\end{array}$ & 1 & 0 & 1 & 0 & 0 & 0 & 1 & 2 & 0 & 1 & 0 & 1 & 0 & 1 & 1 & 0 & 1 & 1 & 0 & 0 & 0 & 1 & 1 & 1 & 0 & 2 & 1 & 0 & 0 & 0 & 1 & 0 & 0 & 0 & 0 & 1 & 0 \\
\hline $\begin{array}{l}\text { Eufriesea pulchra } \\
\text { (Smith, 1854) }\end{array}$ & 1 & 0 & 0 & 1 & 0 & 0 & 0 & 1 & 0 & 1 & 0 & 0 & 0 & 0 & 1 & 1 & 1 & 0 & 1 & 0 & 0 & 1 & 0 & 0 & 1 & 1 & 0 & 1 & 1 & 1 & 0 & 0 & 0 & 1 & 1 & 1 & 1 \\
\hline $\begin{array}{l}\text { Eufriesea surinamensis } \\
\text { (Linnaeus, 1758) }\end{array}$ & 1 & 0 & 0 & 1 & 0 & 0 & 0 & 1 & 0 & 1 & 0 & 0 & 0 & 0 & 1 & 1 & 1 & 0 & 1 & 0 & 0 & 1 & 0 & 0 & 1 & 1 & 0 & 1 & 1 & 1 & 0 & 0 & 0 & 1 & 1 & 1 & 1 \\
\hline $\begin{array}{l}\text { Eg. (Glossuropoda) intersecta } \\
\text { Latreille, } 1938\end{array}$ & 1 & 1 & 0 & 2 & 0 & 0 & 0 & 2 & 0 & 1 & 0 & 0 & 1 & 0 & 1 & 1 & 1 & 0 & 1 & 0 & 0 & 1 & 1 & 1 & 0 & 2 & 0 & 1 & 2 & 0 & 0 & 0 & 1 & 1 & 0 & 1 & 0 \\
\hline $\begin{array}{l}\text { Eg. (Euglossella) decorata } \\
\text { Smith, } 1874\end{array}$ & 1 & 1 & 0 & 2 & 0 & 0 & 0 & 2 & 0 & 1 & 0 & 0 & 1 & 0 & 1 & 1 & 1 & 0 & 1 & 0 & 0 & 1 & 1 & 1 & 0 & 2 & 0 & 1 & 2 & 0 & 0 & 0 & 1 & 1 & 0 & 1 & 0 \\
\hline $\begin{array}{l}\text { Eg. (Glossura) ignita } \\
\text { Smith, } 1874\end{array}$ & 1 & 1 & 0 & 2 & 0 & 0 & 0 & 2 & 0 & 1 & 0 & 0 & 1 & 0 & 1 & 1 & 1 & 0 & 1 & 0 & 0 & 1 & 1 & 1 & 0 & 2 & 0 & 1 & 2 & 0 & 0 & 0 & 1 & 1 & 0 & 1 & 0 \\
\hline $\begin{array}{l}\text { Eg.(Euglossa) mourei } \\
\text { Dressler, 1982c }\end{array}$ & 1 & 1 & 0 & 2 & 0 & 0 & 0 & 2 & 0 & 1 & 0 & 0 & 1 & 0 & 1 & 1 & 1 & 0 & 1 & 0 & 0 & 1 & 1 & 1 & 0 & 2 & 0 & 1 & 2 & 0 & 0 & 0 & 1 & 1 & 0 & 1 & 0 \\
\hline $\begin{array}{l}\text { Eg.(Glossurella) augaspis } \\
\text { Dressler, 1982b }\end{array}$ & 1 & 1 & 0 & 2 & 0 & 0 & 0 & 2 & 0 & 1 & 0 & 0 & 1 & 0 & 1 & 1 & 1 & 0 & 1 & 0 & 0 & 1 & 1 & 1 & 0 & 2 & 0 & 1 & 2 & 0 & 0 & 0 & 1 & 1 & 0 & 1 & 0 \\
\hline $\begin{array}{l}\text { Exaerete smaragdina } \\
\text { Guérin, } 1845\end{array}$ & 1 & 0 & 1 & 0 & 0 & 0 & 1 & 2 & 1 & 1 & 0 & 0 & 0 & 0 & 1 & 1 & 1 & 0 & 1 & 1 & 1 & 1 & 1 & 1 & 0 & 2 & 1 & 0 & 2 & 0 & 0 & 0 & 0 & 1 & 0 & 1 & 0 \\
\hline $\begin{array}{l}\text { Eulaema (Eulaema) } \\
\text { bombiformis (Packard, 1869) }\end{array}$ & 0 & 1 & 1 & 1 & 1 & 1 & 1 & 1 & 0 & 1 & 1 & 1 & 1 & 1 & 1 & 0 & 1 & 1 & 1 & 0 & 0 & 1 & 0 & 0 & 1 & 1 & 0 & 1 & 1 & 1 & 0 & 1 & 0 & 1 & 1 & 1 & 0 \\
\hline $\begin{array}{l}\text { E. (Apeulaema) polychroma } \\
\text { (Mocsáry, 1899) }\end{array}$ & 0 & 1 & 1 & 1 & 1 & 1 & 1 & 1 & 0 & 1 & 1 & 1 & 1 & 1 & 1 & 0 & 1 & 1 & 1 & 0 & 0 & 1 & 0 & 0 & 1 & 1 & 0 & 1 & 1 & 1 & 0 & 1 & 0 & 1 & 1 & 1 & 0 \\
\hline
\end{tabular}


era considerado plesiomórfico na primeira hipótese tornou-se derivado na segunda, sem que a autora justificasse essa mudança na interpretação da polaridade.

Aliás, Michener (op. cit.) critica amplamente este último trabalho de Kimsey, principalmente nos seguintes aspectos: 1) dos 25 caracteres utilizados, 16 são exclusivos para cada gênero, ou autapomorfias; 2) dos nove caracteres restantes e que constituiriam sinapomorfias, quatro foram polarizados de modo questionável por Kimsey (1987), com base no fato de estarem restrita ou amplamente distribuídos no grupo interno (segundo a autora, "derivado" ou "primitivo", respectivamente), procedimento esse, amplamente rejeitado pelos cladistas (Amorim, 1994).

Diante de tais dificuldades, Michener (op. cit.) apresenta um arranjo para as relaçôes filogenéticas obtidas por Kimsey (1987) (Fig. 10-c), alegando que isso era o máximo que se poderia obter naquela ocasiāo.
Segundo Engel (1999), uma das diferenças mais marcantes entre sua hipótese de filogenia e as dos autores que o precederam consiste na posição do gênero Eufriesea. Para ele, tanto Kimsey (1982, 1987) quanto Michener (1990) agruparam Eufriesea com os gêneros Eulaema e Aglae, ao passo que em seu trabalho ficou agrupada com o clado Euglossa-Exaerete spp. Entretanto, não é isso o que ocorre em Kimsey (1982), onde Aglae é o grupoirmão de todos os Euglossini. Além do mais, discordo da interpretação dele a respeito de dois caracteres em Aglae: 1) ele considerou a fenda tibial ampla e ovóide, mas a considero estreita e curva na base (apomórfica); 2) ele considerou que a mesma fenda tibial alcança o ápice da tíbia, mas em minha interpretação isso não ocorre. Assim, se na matriz de Engel (1999), alterarmos de 0 para 1 os estados dos caracteres 6 e 7 para o gênero Aglae, o resultado seria (Aglae (Eufriesea, Eulaema)) (Euglossa, Exaerete spp.))), portanto semelhante aos dos autores por ele citados.

Apesar desses autores apresentarem supostas autapomorfias de Eulaema, eles não testaram a monofilia do mesmo, pois não

Tabela 2 - Matriz de dados para as espécies do gênero Eulaema e grupo externo.

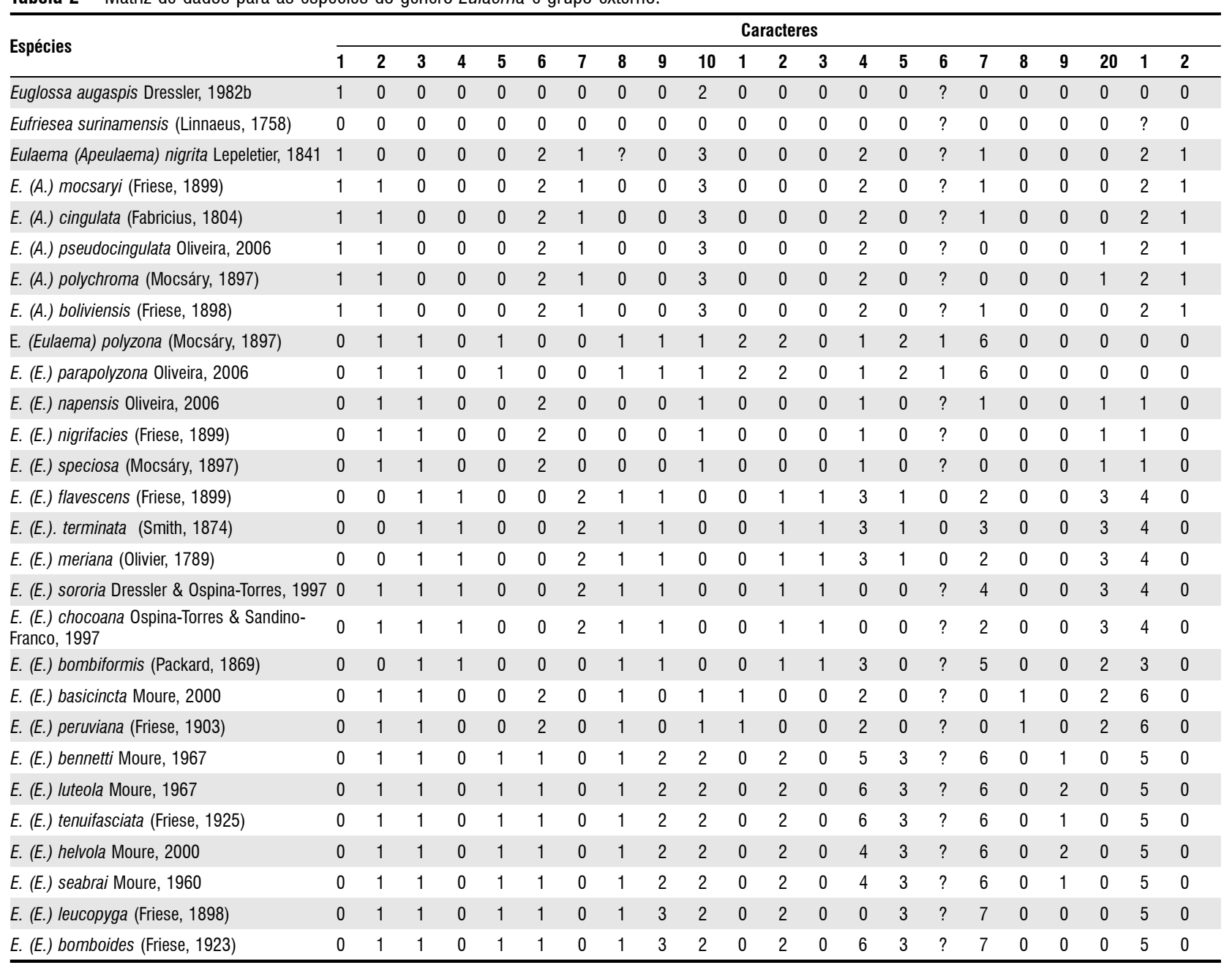


verificaram a variação dos caracteres entre as espécies em uma topologia.

\section{RELACIONAMENTOS FILOGENÉTICOS ENTRE AS ESPÉCIES DE Eulaema}

Na hipótese de filogenia aqui considerada (Fig. 9), o gênero Eulaema é composto de dois grupos monofiléticos que correspondem aos dois subgêneros propostos por Moure (1950): Eulaema s. str. e Apeulaema. Em seu trabalho sobre as genitálias de machos de Eulaema, Ospina-Torres (1998) também admite esses dois subgêneros, embora não tenha apresentado uma hipótese de filogenia suportando-os.

Quatro apomorfias sustentam o clado que agrupa as espécies do subgênero Apeulaema: presença de manchas amarelas na face dos machos, área malar com projeção dentiforme inferior aguda, gonóstilos curtos e com extremidade estreita, e tegumento preto e sem reflexos metálicos. O subgênero Apeulaema é composto pelos grupos polychroma (E. polychroma, E. pseudocingulata) e nigrita (E. nigrita, E. mocsaryi, E. cingulata, E. boliviensis). Entretanto, o único caráter que suporta o primeiro grupo, projeção lateral do oitavo esterno curta e arredondada, ocorre também no grupo speciosa, do subgênero Eulaema, o que sugere uma homoplasia. O grupo nigrita, também possui um único caráter suportando-o, braços do sétimo esterno curtos e pouco abertos, mas nesse caso trata-se de caráter de surgimento único (Fig. 9).

Três apomorfias sustentam o subgênero Eulaema: clípeo longo, maior que a distância interorbital, asas anteriores com a metade basal enegrecida e o ápice âmbar-claro e tíbia média com área aveludada muito estreita. Esse padrão de asas, porém, não ocorre no grupo speciosa, que possui o padrão âmbar-claro, em sua totalidade. Isso pode ser considerado uma reversão, já que tal condição ocorre ainda em Apeulaema e no grupo-externo. Área aveludada muito estreita, por sua vez, surgiu no ancestral do subgênero Eulaema, mas houve perda dessa condição no grupo meriana, onde a área aveludada é apenas estreita, e no grupo leucopyga, onde ela é ampla, como em Euglossa, indicando uma provável homoplasia.

O subgênero Eulaema é constituído pelos seguintes grupos (Fig. 9):

1) grupo peruviana (E. peruviana, E. basicincta), com quatro apomorfias: região subapical da fenda tibial tão larga quanto a base, presença de saliências nos braços do sétimo esterno, projeção lateral do oitavo esterno curta e pontiaguda e ainda gonóstilos moderadamente longos e terminando em ponta estreita;

2) grupo speciosa (E. napensis, E. nigrifacies, E. speciosa), com uma única apomorfia, gonóstilos curtos e moderadamente largos;

3) grupo meriana (E. sororia, E. chocoana, E. bombiformis, $E$. flavescens, E. terminata, E. meriana), com seis apomorfias: área malar maior que o diâmetro do flagelômero, área malar com projeção dentiforme inferior rombuda, pêlos do bordo posterior dos basitarsos das pernas posteriores um pouco mais longos que a maior largura do basitarso, bordo posterior do sexto tergo metassomático levemente projetado no meio, projeção lateral do oitavo esterno longa e pontiaguda, gonóstilos longos e com extremidade estreita;

4) subgrupo polyzona (E. polyzona, E. parapolyzona), com três apomorfias: região apical da fenda tibial mais larga que a base, pilosidade do quinto esterno muito fina e reduzida a uma fileira no bordo posterior, a mesma fileira situada muito próximo ao bordo;

5) subgrupo leucopyga (E. luteola, E. helvola, E. leucopyga, $E$. bomboides, E. bennetti, E. tenuifasciata e $E$. seabrai), com quatro apomorfias: área genal com projeção dentiforme interna moderada, tíbia média com área aveludada curta, tíbia média com área aveludada ampla, ausência de pilosidade no quinto esterno.

Dressler (1979), tendo por base o caráter 'aspecto do bordo posterior do quinto esterno', sugeriu que o subgênero Eulaema poderia ser dividido em dois grupos de espécies, um composto por E. seabrai, E. polyzona, E. bomboides e E. leucopyga e outro por E. meriana, E. bombiformis, E. peruviana e E. speciosa. De acordo com os resultados aqui obtidos, o primeiro grupo proposto por Dressler seria monofilético, ainda que composto por mais espécies, ao passo que o segundo seria parafilético e constituído de três grupos, todos com um número maior de espécies: a) peruviana, b) speciosa e c) meriana, este contendo E. bombiformis. Por outro lado, Michener (1990) nos dá a informação de que Dressler reconhecia quatro grupos de espécies para o gênero Eulaema, mas que o mesmo não esclarece se isso justificaria a constituição de novos subgêneros.

De acordo com os resultados de Ospina-Torres (1998), o subgênero Eulaema poderia ser dividido em três grupos de espécies: i) meriana, formado por $E$. meriana, E. bombiformis, $E$. sororia e E. chocoana; ii) seabrai, formado por E. seabrai, E. speciosa e E. peruviana e iii) leucopyga, formado por E. leucopyga, $E$. bomboides e E. polyzona. Quando comparados aos resultados aqui obtidos, apenas o primeiro e o terceiro parecem constituir grupos naturais.

\section{AGRADECIMENTOS}

Ao Dr. João M. F. Camargo pela orientação, aos curadores e instituiçóes pelo empréstimo de material, aos dois consultores anônimos pelas críticas e sugestôes.

\section{BIBLIOGRAFIA}

Amorim, D.S. 1994. Elementos Básicos de Sistemática Filogenética. São Paulo, Sociedade Brasileira de Entomologia, xii + 314 pp.

Dressler, R.L. 1979. Eulaema bombiformis, E. meriana, and mullerian mimicry in related species (Hymenoptera: Apidae). Biotropica 11 (2): 144-151. 


\section{ACTA}

Engel, M.S. 1999. The first fossil Euglossa and phylogeny of the orchid bees (Hymenoptera: Apidae: Euglossini). American Museum Novitates 3272: 1-14.

Kimsey, L.S. 1982. Systematics of bees of the genus Eufriesea (Hymenoptera, Apidae). University of California Publications (Entomology) 95: 1-125.

Kimsey, L.S. 1987. Generic relationships within the Euglossini (Hymenoptera, Apidae). Systematic Entomology 12: 63-72.

Michener, C.D. 1990. Classification of the Apidae (Hymenoptera). University of Kansas Science Bulletin 54 (4): 75-164.

Michener, C.D.; M.L Winston \& R. Jander. 1978. Pollen manipulation and related activities and strucutures in bees of the family Apidae. University of Kansas Science Bulletin 51 (19): 575-601.

Moure, J.S. 1950. Contribuição para o conhecimento do gênero Eulaema Lepeletier (Hymen.- Apoidea). Dusenia 1 (3): 181200.
Moure, J.S. 2000 [2003]. As espécies do gênero Eulaema Lepeletier, 1841 (Hymenoptera, Apidae, Euglossinae). Acta Biologica Paranaense 29(1,2,3,4): 1-70.

Oliveira, M.L. 2006. Três novas espécies de abelhas da Amazônia pertencentes ao gênero Eulaema (Hymenoptera, Apidae, Euglossinae). Acta Amazonica 36(1): 121-128.

Ospina-Torres, R. 1998. Revisión de la morfologia genital masculina de Eulaema (Hymenoptera: Apidae). Revista de Biologia Tropical 46 (3): 749-762.

Peruquetti, R.C. 2002. Dimorfismo sexual em machos de Euglossa mandibularis Friese (Apidae, Euglossina). Revista Brasileira de Zoologia 19(4): 1223-1226.

Poinar JR., G. 1999. Paleoeuglossa melissiflora gen. n., sp. n. (Euglossine; Apidae), fossil orchid bees in dominican amber. Journal of the Kansas Entomological Society 71 (1): 29-34.

Recebido em 14/11/2002

Aceito em 24/01/2006 